\title{
STUDY ON FIBER FURNISHES AND FIBER MORPHOLOGICAL PROPERTIES OF COMMONLY USED INDIAN FOOD PACKAGING PAPERS AND PAPERBOARDS
}

\author{
SWATI SOOD and CHHAYA SHARMA \\ Environmental Research Laboratory, Department of Paper Technology, \\ Indian Institute of Technology Roorkee, Saharanpur Campus, Saharanpur, 247001, India \\ Corresponding author: Chhaya Sharma, chhaya1964@rediffmail.com
}

Received September 16, 2020

\begin{abstract}
Maintaining the quality of their final paper-based food packaging products at a high and constant level is a key issue for food packaging manufacturers to meet the customer demands. In the present study, in order to analyze the present status of quality of paper-based food packages in India, the fiber furnishes of different common paper- and paperboardbased food packages were studied by the Graff "C" staining test and their fiber morphological properties - by MorFi analysis. The staining test results showed that all the samples contained fiber furnish made either by the chemical or by the mechanical pulping process. Tea bags, dry fruit boxes and egg trays were made of 4 different fiber components, while sugar sachets and juice boxes contained 3 fiber components. It was also observed that all the samples contained hardwood and softwood chemical fibers. MorFi analysis determined the morphological properties of the fibers, including the mean fiber length and width, coarseness, kink angle, kinked fibers $\%$, curl $\%$ and fines elements $\%$ in total analyzed fibers. The results thus obtained confirmed that both these techniques are very reliable and feasible tools to study the quality of paper-based food packages.
\end{abstract}

Keywords: papers and paperboards, food packages, fiber furnish, Graff "C" staining, MorFi analysis, fiber morphological properties

\section{INTRODUCTION}

In the recent few years, there has been a rising demand for paper- and paperboard-based food packages, which can be explained to the changing lifestyle and eating habits of the population., ${ }^{1,2}$ Nowadays, the production of paper- and paperboard-based food packages has transitioned from wood to non-wood fiber sources, such agroresidues, and the preference for non-wood fiber sources is predicted to increase drastically in the next few years, due to the diminishing forest resources, scarcity of commonly used raw materials for pulping, the easy availability of agro-residues, the increasing demand for paperbased products, rising environmental pressure, and consequent policies in favor of the environment. $^{3-5}$ There are several advantages of utilizing agro-residues for pulping, e.g. faster and shorter growth cycles, very low requirement of irrigation and fertilization, as well as their low lignin content, consequently, the energy and chemicals that are required during pulping are also lower. ${ }^{6}$ However, the result of using different sources of fibers for pulp production, i.e. wood and non-wood fibers, is that the fibers commonly utilized in the industries have become highly variable. $^{7}$

At the present consumption rate of fast-food and other food items served in paper-based food packages, the expected increase in the use of paper products will require a considerably higher utilization of various fibers, while keeping in mind that the goal of the food packaging paper and paperboard industry is to make products that meet customer specifications and requirements. ${ }^{8}$ Thus, to maintain the quality of the final products and to continue the competitiveness of the paperbased food packaging industry, it is crucial to have an understanding of the relationship between pulp fibers, their morphological properties and their effects on paper properties. To this end, the characterization of fibers and of the pulp 
composition is required to be performed in a systematic manner.

The aim of this study was, therefore, to analyze the fiber furnish composition and fiber morphological properties in commonly used food packaging papers and paperboards in India, as, to the best of our knowledge, no such study has been undertaken before.

\section{EXPERIMENTAL}

\section{Classification of samples}

A total of 5 different types of food packaging papers and paperboards were collected from restaurants, canteens, cafeterias and food joints from different places in India. The collected samples were divided into 2 categories based on grammage (weight per unit area), which was calculated according to TAPPI test method (T410). The materials below 224 $\mathrm{g} / \mathrm{m}^{2}$ were classified as papers, while materials above $224 \mathrm{~g} / \mathrm{m}^{2}$ were classified as paperboards, as shown in Table $1 .^{10}$

\section{Graff “C”' staining test}

An amount of $0.5 \mathrm{~g}$ of sample was taken and torn into small pieces. The pieces were then placed in a beaker, which was filled with water so that the sample was soaked completely. After a while, the water was decanted and the pieces were rolled into small pellets between the fingers. The pellets were placed in a large test-tube with water and shaken vigorously with constant addition of small quantities of water from time to time, until the paper was thoroughly defibered. Meanwhile, a glass slide was placed on a hot plate of about $50-60{ }^{\circ} \mathrm{C}$. $0.5 \mathrm{~mL}$ of the fiber suspension was placed on the center of the slide. As the water evaporated, the slide was gently taped and the fibers were arranged with the help of a needle. After drying, the slides were cooled and stained with 2-3 drops of Graff "C" stain. A cover slip was placed on the stained portion of the slide. The slides were then observed under the microscope (Olympus BX51 TRF, Japan).

For qualitative identification, the colors of the various fibers were observed by moving the slides backward and forward, as well as sideways, so that the entire stained area was covered. The observed fiber colors and the morphological peculiarities, such as shape, size and pitting, were compared with the standard morphologies presented in IS 5285:1998. For quantitative analysis, the total fibers were counted in 5 different lines, with each line being $5 \mathrm{~mm}$ apart and the overall number of each fiber type was multiplied with its specific mass factor and converted to the percentage value to determine its weight in the pulp. ${ }^{11}$

\section{MorFi analysis}

A MorFi fiber analyzer v9.6 (Techpap, France) was used in order to study the morphological properties of the fibers. $3 \mathrm{~g}$ of sample was mixed in $1 \mathrm{~L}$ of distilled water, i.e. $0.3 \%$ solids content, to form an aqueous suspension, which was passed through a measuring cell by a pump and a high resolution digital camera was used to take pictures. ${ }^{12}$ The pictures were then analyzed using the software system, which calculated the morphological properties, such as mean length, width, coarseness, kink angle, kinked fibers $\%$, curl\%, and fines elements\% of the total analyzed fibers by the skeletonization process, in which each segment path was scanned. ${ }^{13}$

All the measurements were performed in three replicates. The data determined were expressed as the mean of the three replicate determinations and presented as means \pm SD.

Table 1

Classification of food packages on the basis of grammage

\begin{tabular}{lcc}
\hline Samples & Grammage $\left(\mathrm{g} / \mathrm{m}^{2}\right)^{*}$ & Category of samples \\
\hline Tea bag & $20.71 \pm 0.59$ & Paper \\
Sugar sachet & $26.13 \pm 0.12$ & Paper \\
Juice box & $279.66 \pm 3.51$ & Paperboard \\
Dry fruit box & $421.1 \pm 0.65$ & Paperboard \\
Egg tray & $509.66 \pm 1.52$ & Paperboard \\
*alues are shown as mean \pm SD & &
\end{tabular}

\section{RESULTS AND DISCUSSION}

The fibers used for making paper and paperboard food packages are generally obtained from either hardwoods, softwoods or agroresidues. The characteristic feature of hardwoods is the presence of vessel elements, while softwoods are identified on the basis of pits and agro-residues by the presence of epidermal cells. ${ }^{14}$ Table 2 shows the different fibers present in the food packaging samples under study and their quantity. In tea bags, it was found that the maximum number of fibers represented hardwood chemical fibers $(36.23 \pm 0.45 \%)$. Similarly, in sugar sachets, the majority of fibers were hardwood chemical fibers $(63.96 \pm 0.15 \%)$. On the other hand, juice boxes had the highest number of softwood chemical fibers $(61.66 \pm 0.25 \%)$, while dry fruit boxes - the highest number of agro- 
residue chemical fibers $(55.06 \pm 0.15 \%)$, and egg trays - the highest number of softwood mechanical fibers $(43.36 \pm 0.30 \%)$. The results show that agro-residues were present in the highest amount in only one of the samples. This can be explained by the fact that, although agroresidues are side harvests, they fulfill dual purposes of waste utilization, in addition to being used for replacement of wood-based fibers. However, agro-residue fibers are short and contain a large quantity of non-fibrous components, which has an adverse effect on the mechanical and strength properties of the paper. Thus, in paper-making, the wood pulp cannot be entirely replaced by agro-residues, as this would lower the standards of paper properties. A recent study showed that, on combining hardwood pulp with agro-residues, there was an enhancement in the properties of paper, compared to the paper made entirely from agro-residue pulp. The study reported that the combination of $85 \%$ agroresidue content with $15 \%$ hardwood content provided paper properties comparable to those of a sheet made completely from hardwood. ${ }^{15}$

Table 2

Fiber composition of food packaging paper and paperboard samples

\begin{tabular}{lcccc}
\hline Sample & $\begin{array}{c}\text { Hardwood } \\
\text { chemical, \%* }\end{array}$ & $\begin{array}{c}\text { Softwood } \\
\text { chemical, \%* }\end{array}$ & $\begin{array}{c}\text { Softwood } \\
\text { mechanical, \%* }\end{array}$ & $\begin{array}{c}\text { Agro-residue } \\
\text { chemical, \%* }\end{array}$ \\
\hline Tea bag & $36.23 \pm 0.45$ & $24.43 \pm 0.50$ & $16.43 \pm 0.25$ & $22.03 \pm 0.40$ \\
Sugar sachet & $63.96 \pm 0.15$ & $23.23 \pm 0.25$ & $12.8 \pm 0.3$ & - \\
Juice box & $8.83 \pm 0.20$ & $61.66 \pm 0.25$ & - & $29.43 \pm 0.35$ \\
Dry fruit box & $11.53 \pm 0.30$ & $7.46 \pm 0.20$ & $25.93 \pm 0.15$ & $55.06 \pm 0.15$ \\
Egg tray & $10.3 \pm 0.2$ & $12.46 \pm 0.30$ & $43.36 \pm 0.30$ & $33.6 \pm 0.2$ \\
\hline *alues are shown
\end{tabular}

$*$ values are shown as mean $\pm \mathrm{SD}$

The first step in the paper-making process consists in pulping of raw materials. Mechanical pulping is the process in which the fibers are ground, while the lignin content remains intact. On the other hand, in chemical pulping, the lignin is removed. Graff " $\mathrm{C}$ " stain reacts with lignin to produce a yellow color. Actually, in this test, the stain has a double function: on the one hand, it accentuates the fiber details, and on the other, it reveals the content of lignin in the fiber, by imparting a range of colors, from yellow to blue, to the fibers, as a function of the amount of lignin present in the fiber. Hence, mechanical fibers are stained yellow, as the stain reacts with lignin, while chemical fibers are stained gray to blue, as there is no or very little lignin present. ${ }^{16}$

In Figure 1 (a-e), the fibers in yellow are identified as mechanical fibers and the ones stained blue are chemical fibers. The wide fibers belong to softwoods, exhibiting the presence of pits. The medium length fibers are of agroresidues, with epidermal cells, while the short fibers belong to hardwoods, displaying vessels.

It is well known that different methods of paper production, such as chemical and mechanical pulping, affect the bonding ability of the fibers, which in turn influences the strength properties of the paper and paperboard. For example, during the process of mechanical pulping, the fibers get damaged, and because of this, the paper and paperboard that are formed are weak in nature. The main use of mechanical pulp is in the manufacturing of tissue papers and paper-based materials in which high levels of strength are not required. In chemical pulping, lignin is removed by the delignification process, which results in a relatively higher strength paper due to increased contact between the fibers in the finished sheet, in comparison with a sheet that is made from fibers with high lignin content, as produced by mechanical pulping. Moreover, the fiber length and quality of chemical pulp are higher, and the fibers are more uniform in comparison with those of mechanical pulp, as it contains less lignin and other constituents of wood, hence more cellulose, and the fibers are intact. Thus, a sheet of paper or paperboard produced by chemical pulping is stronger than that prepared by mechanical pulping. ${ }^{17}$

The physical properties of a pulp sheet largely depend upon its fiber composition. According to earlier studies, the relationship between fiber composition and physical properties in hardwoods is not as strong as the relationship between fiber composition and physical properties in softwoods. The most probable reason for this is the heterogeneous nature of hardwoods. Previous studies have reported that this effect of fiber properties on the strength of the paper caused a general belief that only long softwood fibers could be used for making high strength papers. ${ }^{18}$ 

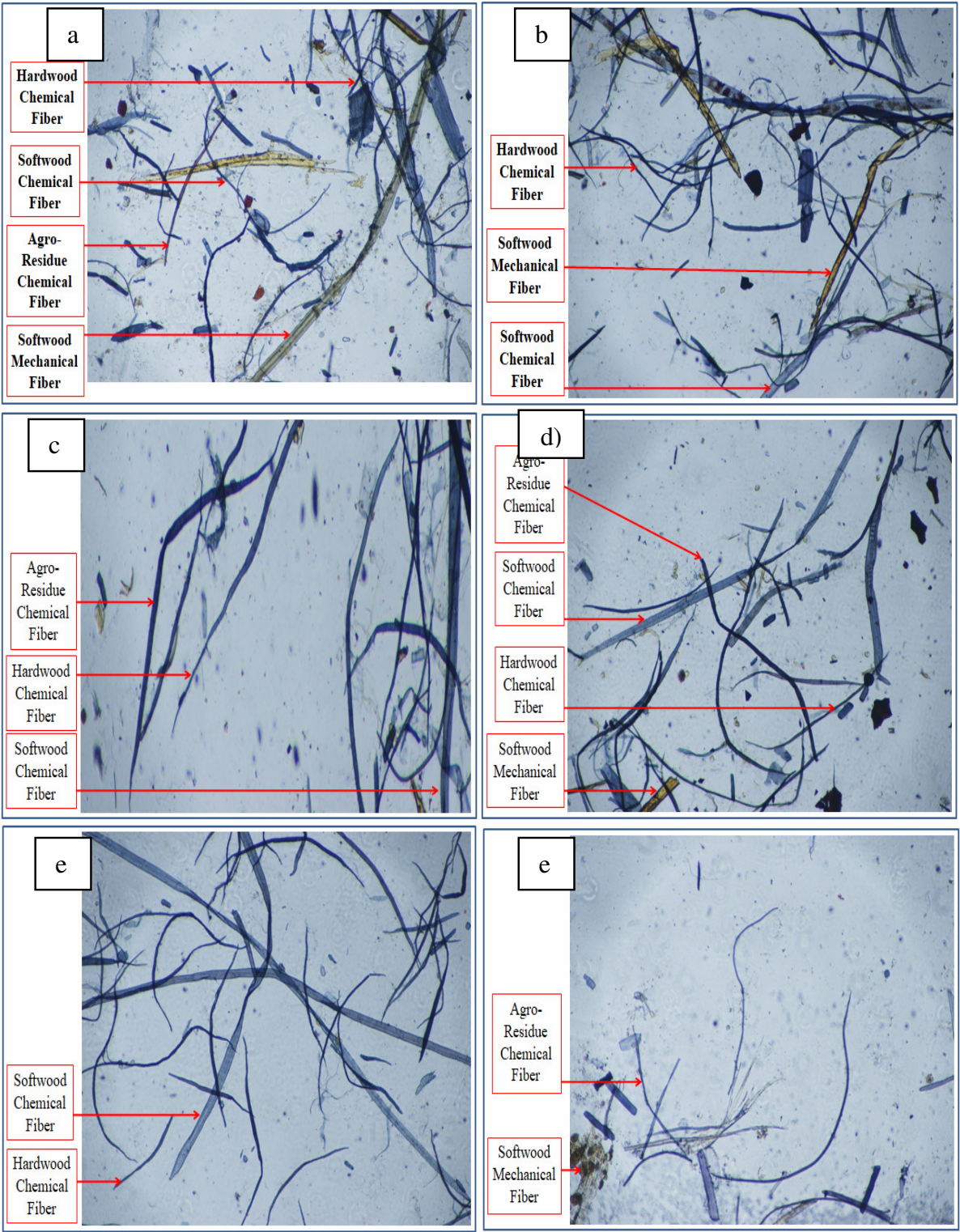

Figure 1: Optical micrographs of samples observed at 50x: a) tea bag, b) sugar sachet, c) juice box, d) dry fruit box and e) egg tray

However, the latest research findings show encouraging results regarding wheat straw, which is an agro-residue and still demonstrated good mechanical sheet properties and could be thus considered for fully or partially replacing the use of conventional raw materials. ${ }^{19}$ The average ranges of Indian hardwood, softwood and agro-residue fibers length and width in $\mu \mathrm{m}$, as mentioned in IS 5285:1998, are as follows: hardwood (length: 350-1600, width: 6-45), softwood (length: 800-6500, width: 20-60) and agro-residues (length: 600-4520, width: 4-25). The mean length and width of the fibers observed in the present study were calculated and listed in Table 3.
The values reported in Table 3 are in accordance with the average ranges of Indian fiber dimensions stipulated in IS 5285:1998. The morphological properties of fibers determined in in this study and included in Table 3 are coarseness, kink angle, kinked fiber, $\%$, curl, $\%$, fines elements, $\%$, and the total number of fibers analyzed.. The microuniformity of paper is highly influenced by fiber length, as it affects the strength properties of paper. On the other hand, an increase in the percentage of fibers having higher width leads to better paper formation due to an increase in cohesion. As shown in Table 3, juice boxes contained fibers with the highest mean length $(1395 \pm 5.29 \mu \mathrm{m})$ and width $(32.33 \pm 0.66 \mu \mathrm{m})$. 
Table 3

Morphological properties of fibers in different samples

\begin{tabular}{|c|c|c|c|c|c|c|c|c|}
\hline Sample & $\begin{array}{l}\text { Mean fiber length } \\
(\mu \mathrm{m})^{*}\end{array}$ & $\begin{array}{l}\text { Mean fiber width } \\
(\mu \mathrm{m})^{*}\end{array}$ & $\begin{array}{c}\text { Coarseness } \\
(\mathrm{mg} / \mathrm{m})^{*}\end{array}$ & $\begin{array}{c}\text { Kink angle } \\
\left({ }^{\circ}\right)\end{array}$ & $\begin{array}{c}\text { Kinked fibers } \\
(\%)^{*}\end{array}$ & $\begin{array}{l}\text { Curl } \\
(\%)^{*}\end{array}$ & $\begin{array}{c}\text { Fines elements } \\
\text { (\% in area)* }\end{array}$ & $\begin{array}{c}\text { Total fibers } \\
\text { analyzed }\end{array}$ \\
\hline Tea bag & $834.66 \pm 3.51$ & $25.33 \pm 0.55$ & $1.20 \pm 0.00$ & 129 & $27.13 \pm 0.15$ & $10.33 \pm 0.15$ & $27.33 \pm 0.01$ & 5028 \\
\hline Sugar sachet & $831 \pm 3$ & $23.23 \pm 0.32$ & $0.03 \pm 0.00$ & 127 & $17.7 \pm 0.2$ & $7.35 \pm 0.13$ & $15.81 \pm 0.02$ & 5091 \\
\hline Juice box & $1395 \pm 5.29$ & $32.33 \pm 0.66$ & $0.16 \pm 0.00$ & 134 & $25.56 \pm 0.15$ & $9.61 \pm 0.07$ & $11.04 \pm 0.03$ & 5008 \\
\hline Dry fruit box & $827 \pm 5.56$ & $24.5 \pm 0.6$ & $0.13 \pm 0.00$ & 134 & $17.9 \pm 0.1$ & $6.70 \pm 0.14$ & $17.05 \pm 0.04$ & 5019 \\
\hline Egg tray & $895.33 \pm 6.02$ & $21.4 \pm 0.55$ & $0.05 \pm 0.00$ & 132 & $27.9 \pm 0.1$ & $7.93 \pm 0.15$ & $16.38 \pm 0.02$ & 5033 \\
\hline
\end{tabular}

*values are shown as mean \pm SD

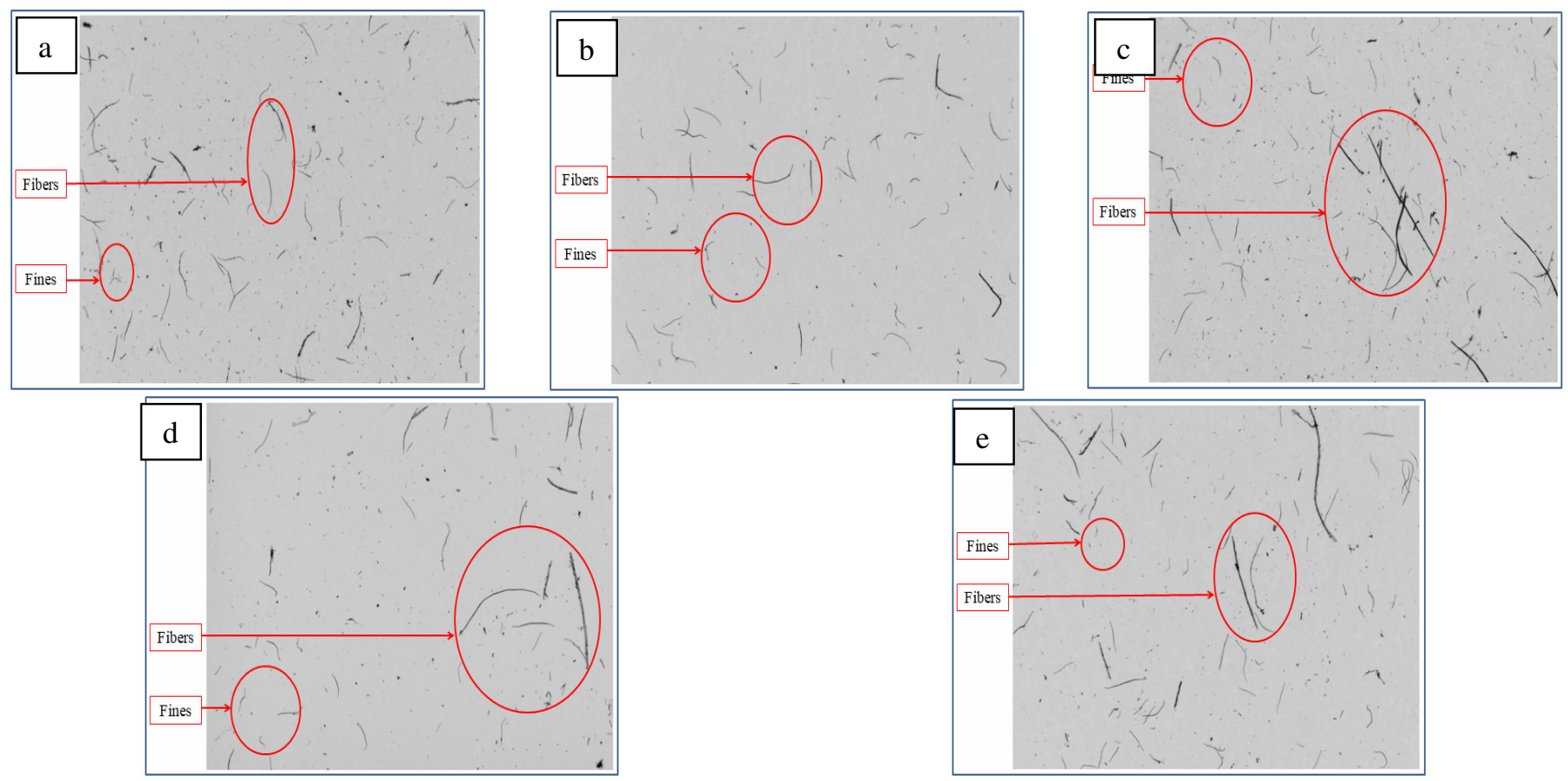

Figure 2: MorFi images of samples: a) tea bag, b) sugar sachet, c) juice box, d) dry fruit box, and e) egg tray 
Coarseness determines the uniformity of the sheet through the number of contacts among the fibers. This influences the structural, strength and optical properties of the paper. An increase in curl and kink causes an increased tear index and decreases the burst as well as tensile index of the paper sheets. In the present study, juice boxes and dry fruit boxes were found to have the maximum kink angle $\left(134^{\circ}\right)$, whereas egg trays showed the maximum number of kinked fibers $(27.9 \pm 0.1 \%)$. Curl in fibers is generated due to bending and stretching, which occurs during pulp formation, its mixing and the refining process. The presence of fines in paper is related to its optical and strength properties, as well as to the smoothness and structure of the paper. According to the results, tea bag fibers presented the maximum level of coarseness $(1.20 \pm 0.00 \mathrm{mg} / \mathrm{m})$, curl level $(10.33 \pm 0.15 \%)$, as well as number of fines $(27.33 \pm 0.01 \%)$, and thus were comparatively smoother in texture than those of other samples.

Figure 2 (a-e) presents the Morfi images of the samples showing the structures of fibers and fines. According to the MorFi program, fibers are identified as elements within the range of length of $100-10000 \mu \mathrm{m}$, and width of 5-75 $\mu \mathrm{m}$, while fines are identified as elements having length $<100 \mu \mathrm{m}$ and width $<5 \mu \mathrm{m}$.

Fines are generated due to the damages caused to the fibers by the use of chemicals, as well as by strong mechanical actions, such as stirring, beating, screening and dispersion, which take place during the pulping process. Hence, during the entire process of paper-making, the length and width of fibers decreases as a result of fiber breaking and, because of this, a large number of fines are produced. These broken and shortened fibers form a matrix with a reasonably low number of hollow spaces, which supports the making of comparatively homogenous paper sheets. These paper sheets also have improved optical properties, such as brightness and opacity. ${ }^{9,20}$

Since different paper and paperboard products require different raw material characteristics, one cannot say that any one kind of fiber is desirable or undesirable, without specifying the end-use of the product. Hence, it is pertinent to select the fibrous composition for making the desired paper and paperboard as a function of the ultimate use of the product. Thus, for a more economically and effectively justified use of paper and paper products in food packaging, the study of fiber furnishes and fiber morphological properties in currently available paper-based food packages will help in assessing if the proper fiber composition has been used, as well as taking the right decision in selecting the appropriate raw materials for each end-use. ${ }^{21}$

\section{CONCLUSION}

The findings of this study show that the Graff "C" staining test and MorFi analysis can be used as research tools for studying the fibers in the food packaging papers and paperboards. The Graff "C" staining test helped identify the pulping method used, as well as the amount of different types of fibers present in each specific type of paper and paperboard, while MorFi analysis revealed the morphological properties of the fibers. Therefore, these study techniques will be helpful for the food packaging industry in assessing the fiber composition of the manufactured products.

ACKNOWLEDGEMENT: The authors are grateful to IIT Roorkee, Saharanpur Campus, and Central Pulp and Paper Research Institute (CPPRI), Saharanpur, for providing the guidance and laboratory facilities to carry out this research work.

\section{REFERENCES}

1 G. X. Ayala, M. Rogers, E. M. Arredondo, N. R. Campbell, B. Baquero et al., Obesity, 16, 1002 (2008), http://doi.org/10.1038/oby.2008.34

2 M. Gehlhar and A. Regmi, New Directions in Global Food Markets. Agriculture Information Bulletin, AIB-794, 2005, p. 5, https://www.ers.usda.gov/webdocs/publications/42581/ 30119_aib794c_002.pdf?v=7593.5

3 D. Kaur, N. K. Bhardwaj and R. K. Lohchab, Waste Manag., $\quad$ 60, $127 \quad$ (2017), https://doi.org/10.1016/j.wasman.2016.08.001

4 S. Ates, I. Deniz, H. Kirci, C. Atik and O. T. Okan, Turk. J. Agric. For., 39, 144 (2015), http://doi.org/10.3906/tar-1403-41

M. Kiaei, S. Mahdavi, A. Kialashaki, M. Nemati, A. Samariha et al., Cellulose Chem. Technol., 48, 105 (2014), https://cellulosechemtechnol.ro/pdf/CCT12(2014)/p.105-110.pdf

6 C. Ververis, K. Georghiou, N. Christodoulakis, P. Santas and R. Santas, Ind. Crop. Prod., 19, 245 (2004), https://doi.org/10.1016/j.indcrop.2003.10.006

7 S. Adamopoulos and J. V. Oliver, Wood Fiber Sci., 38, $\quad 567 \quad$ (2007), https://core.ac.uk/download/pdf/236632184.pdf

8 E. Deisenroth, C. Jho, M. Haniff and J. Jennings, 
Surface Coat. Int., 81, $440 \quad$ (1998), https://link.springer.com/article/10.1007/BF02692974

A. Moral, M. C. Monte, E. Cabeza and A. Blanco, Cellulose Chem. Technol., 44, 473 (2010), https://www.cellulosechemtechnol.ro/pdf/CCT10(2010 /p.473-480.pdf

G. A. Smook and M. J. Kocurek, "Handbook for Pulp and Paper Technologists", Tappi Press, 1982, https://imisrise.tappi.org/TAPPI/Products/02/SMO/020 2SMOOK4.aspx

11 Bureau of Indian Standards IS 5285:1998 Fibre Analysis of Paper and Board - Methods of Test (1998), https://archive.org/details/gov.in.is.5285.1998/page/n1 $1 /$ mode/2up

12 C. H. Ko, S. Y. Leu, C. C. Chang, C. Y. Chang, Y. C. Wang et al., BioResources, 10, 5744 (2015), https://bioresources.cnr.ncsu.edu/resources/combiningcellulosic-ethanol-fermentation-waste-and-municipalsolid-waste-derived-fiber-with-a-kraft-black-liquorderived-binder-for-recycled-paper-making/

13 A. Bartl, B. Mihalyi and I. Marini, Chem. Biochem. Eng. Q., 18, $21 \quad$ (2004), http://pierre.fkit.hr/hdki/cabeq/pdf/18_1_2004/Bartl\%2 0CABEQ_2004_01-4.pdf

14 S. Adamopoulos, IAWA J., 27, 153 (2006), https://brill.com/view/journals/iawa/27/2/articlep153_4.xml
15 S. Bhardwaj, N. K. Bhardwaj and Y. S. Negi, J. Clean. Prod., 213, 134 (2019), https://doi.org/10.1016/j.jclepro.2018.12.143

16 J. H. Woodward, Microsc. Microanal., 8, 196 (2002), https://doi.org/10.1017/S1431927602102303

17 H. Karlsson, Doctoral Thesis, Karlstad University, 2007 , https://www.divaportal.org/smash/get/diva2:5004/FULLTEXT01.pdf 18 R. A. Horn, "Morphology of Pulp Fiber From Hardwoods and Influence on Paper", Forest Products Lab Madison, Wisconsin, 1978, https://apps.dtic.mil/sti/pdfs/ADA054933.pdf

19 S. Guo, H. Zhan, C. Zhang, S. Fu, A. H. Hultén et al., BioResources, 4, $1006 \quad$ (2009), https://bioresources.cnr.ncsu.edu/resources/pulp-andfiber-characterization-of-wheat-straw-and-eucalyptuspulps-a-comparison/

A. Alfaro, F. Lopez, A. Perez, J. C. García, M. A. Pelach et al., Cellulose Chem. Technol., 47, 765 (2013), https://www.cellulosechemtechnol.ro/pdf/CCT910(2013)/p.765-775.pdf

21 O. A. Oluwafemi, Am.-Eurasian J. Agric. Environ. Sci., $\quad$ 2, $359 \quad$ (2007), https://scinapse.io/papers/2185613896 